\title{
Aggressive middle turbinate osteoblastoma with intracranial extension: a case report
}

\author{
Draško Cikojević ${ }^{*}, Z^{2}$ aviša Čolović ${ }^{1}$, Bernarda Lozić ${ }^{2}$ and Marisa Klančnik
}

\begin{abstract}
Introduction: Osteoblastoma is an uncommon benign bone tumor that accounts for 1 percent of all primary bone tumors. About 30 to 40 percent of all osteoblastoma cases involve the spine. Osteoblastoma involving the nasal cavity is rare, with only 11 reported cases in the English-language literature, while only four cases of turbinate osteoblastoma have been described.
\end{abstract}

Case presentation: We report an unusual case of middle turbinate osteoblastoma associated with right-sided nasal obstruction and severe headache in a 14-year-old Caucasian girl. The tumor involved the right middle turbinate, complete anterior and incomplete posterior ethmoidal cells, and the frontal sinus ostium. Cribriform lamina was, in the most part, consumed by the tumor growth, while the skull base was mostly of normal bone structure.

Conclusions: To the best of our knowledge, this is the first case of middle turbinate osteoblastoma with intracranial spread. Surgical treatment is the only therapeutic option for osteoblastoma.

Keywords: Osteoblastoma, Middle turbinate, Nasal obstruction

\section{Introduction}

Osteoblastoma is an uncommon benign bone tumor that accounts for 1 percent of all primary bone tumors [1,2]. The term 'benign osteoblastoma' was independently proposed by Jaffe and Lichtenstein to define a vascular osteoid and bone-forming tumor containing numerous osteoblasts and rich vascularized delicate fibrous stroma with a benign appearance $[3,4]$.

About 30 to 40 percent of all osteoblastoma cases involve the spine $[5,6]$. The most common area of involvement is the cervical spine (20 to 40 percent), followed by the lumbar spine. Approximately 10 to 15 percent arise within the bones of the craniofacial skeleton $[7,8]$. The most common location is the mandible, followed by the maxilla. Osteoblastoma involving the nasal cavity is rare, with only 11 reported cases in the English-language literature $[9,10]$, while only four cases of turbinate osteoblastoma have been described [11-13]. Most nasal cavity cases originate from the ethmoid sinus and spread to involve the nasal cavity. Osteoblastomas usually occur in patients aged $<30$, with a peak incidence in the second

\footnotetext{
* Correspondence: drasko.cikojevic@st.t-com.hr

1Department of Othorinolaryngology, University Hospital Split, Spinčićeva 1,

21000 Split, Croatia

Full list of author information is available at the end of the article
}

decade of life, age range 3 to 78 years. The tumor shows a predilection for male gender ( $\mathrm{M}$ [male]: $\mathrm{F}$ [female], 2.5:1). Most osteoblastomas measure between 2 and $5 \mathrm{~cm}$, and are solid and dark red due to rich vascularity. The tumors have poorly defined margins.

Differential diagnosis of osteoblastoma includes osteoma, osteoid osteoma, chronic osteomyelitis (Brodie's abscess) and osteosarcoma. The treatment of osteoblastoma is principally surgical excision. En bloc resection is usually curative, however, curettage results in a local recurrence rate of approximately 20 percent. Malignant transformation of osteoblastoma to osteosarcoma is exceptionally rare $(<1$ percent).

We report an unusual case of middle turbinate osteoblastoma associated with a right-sided nasal obstruction and severe headache in a 14-year-old Caucasian girl (Figure 1). To the best of our knowledge, this is the first case of middle turbinate osteoblastoma with intracranial spread.

\section{Case presentation}

A 14-year-old Caucasian girl presented with a rightsided nasal obstruction and severe headache, which was most pronounced in the right forehead region. Our patient reported a headache persisting for three years, 


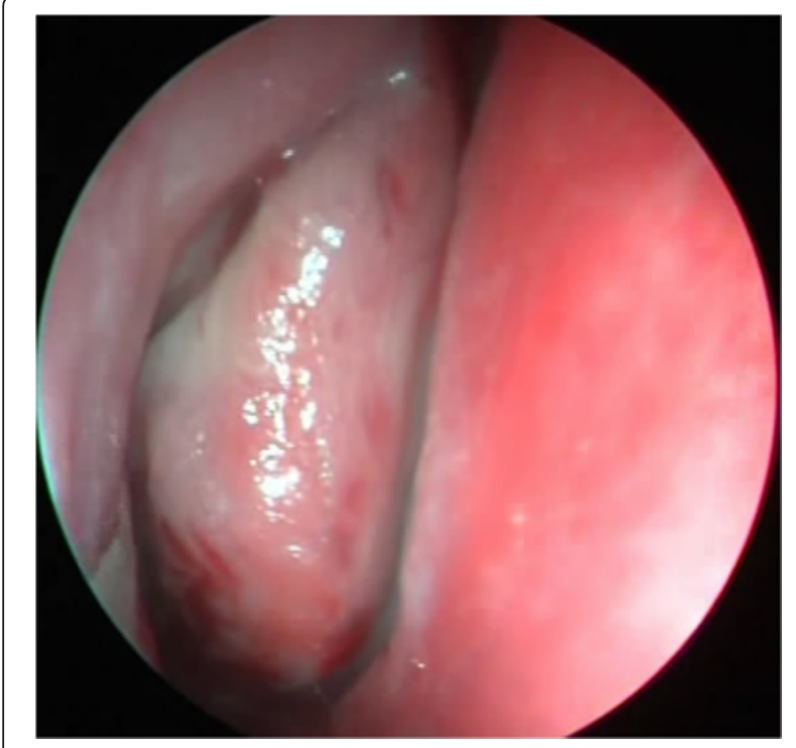

Figure 1 Osteoblastoma of the right middle turbinate.

however, in the past three months, its intensity prevented her from attending school. In addition to difficult breathing on the right turbinate, she reported anosmia and occasional epistaxis on the same nostril. On several occasions, our patient was seen by a pediatrician, who considered her headaches to be related to puberty. When her headache turned so severe to prevent her attending school, a magnetic resonance imaging (MRI) scan of her brain was recommended to reveal a tumor of the right middle turbinate. A multislice computed tomography (MSCT) scan of her paranasal sinuses, taken for better visualization of the bone structure, showed a clearly delineated, heterogeneous (hyperechoic) tumor growth, which corresponded to the finding of a bone tumor with a inhomogeneous central portion and marginal mineralization (Figures 2 and 3). The

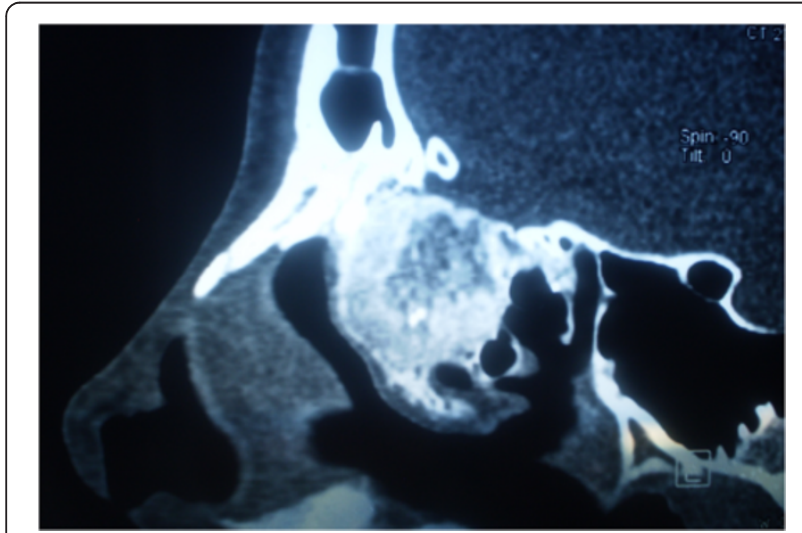

Figure 2 Sagittal multislice computed tomography showed a clearly delineated, heterogeneous (hyperechoic) tumor growth with inhomogeneous central portion and marginal mineralization.

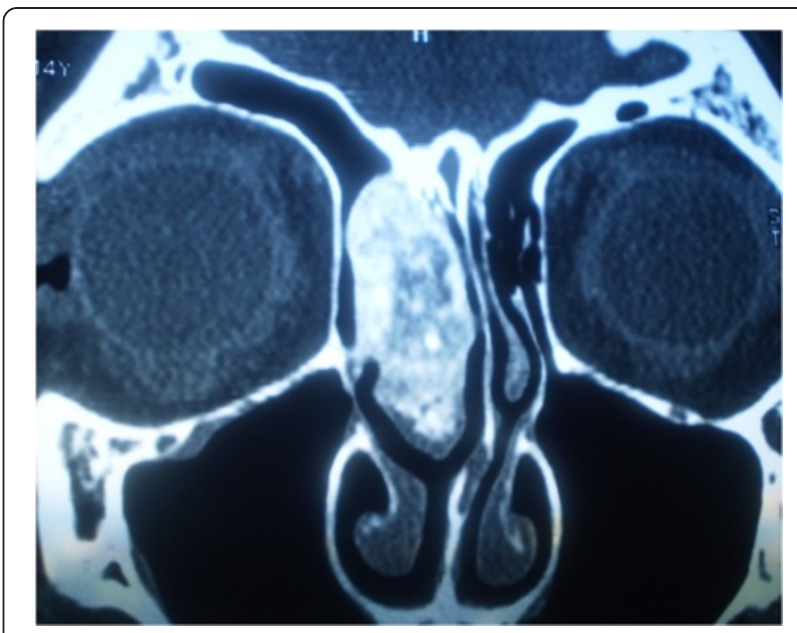

Figure 3 Coronal multislice computed tomography image of osteoblastoma.

tumor involved the right middle turbinate, complete anterior and incomplete posterior ethmoidal cells, and the frontal sinus ostium. Cribriform lamina was, in the most part, consumed by the tumor growth, while the skull base was mostly of normal bone structure. Lamina papyracea was free and clearly demarcated from the tumor. There was septum shift to the left, without septum perforation. The tumor was removed in toto by endoscopic technique (Figure 4) and pathohistological analysis showed the osteoblastoma (Figure 5). As it was a bone tumor, it could not be excised en bloc, instead, the tumor was first cut by a bur in the region of the middle turbinate base, then the rest of the tumor was removed by diamond bur abrasion of the bone with removal of the most part of the cribriform lamina. On endoscopy, there was a clear margin between the healthy bone, which was white and compact, and osteoblastoma, which was of a honeycomb structure, reddish and more

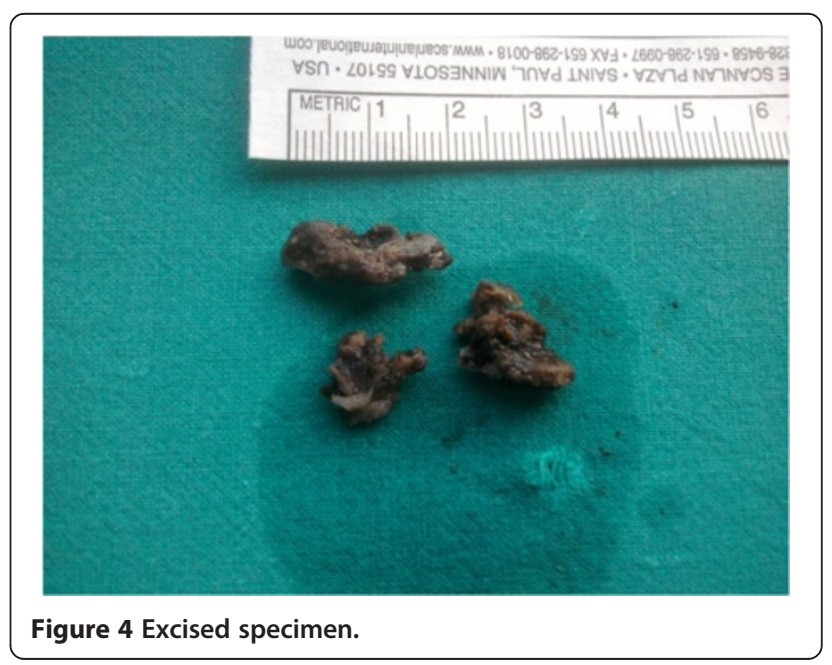




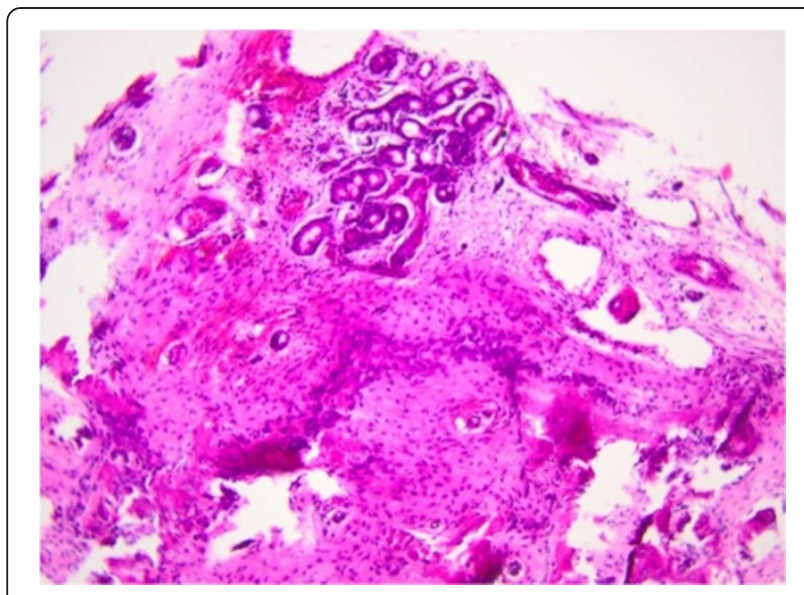

Figure 5 Pathohistologic finding of osteoblastoma, hemotoxylin and eosin $\times 60$.

vascularized. Postoperatively, our patient denied headache, breathed normally through her nose and attended school regularly. But the six-month follow-up computed tomography (CT) scan showed a recurrence and we had to do an en bloc resection of the tumor. The CT scan one year later showed normal findings without recurrence and our patient did not have her headache any more (Figures 6, 7 and 8).

\section{Discussion}

Osteoblastoma is a rare bone tumor and accounts for approximately 1 percent of all primary bone tumors. On differential diagnosis, it is important to differentiate osteoblastoma from osteoma, osteoid osteoma and osteosarcoma.

Osteomas are benign, slow-growing tumors that rarely occur in children. They usually arise on the surface of the cranial vault, jaw, paranasal sinuses and orbit [14].

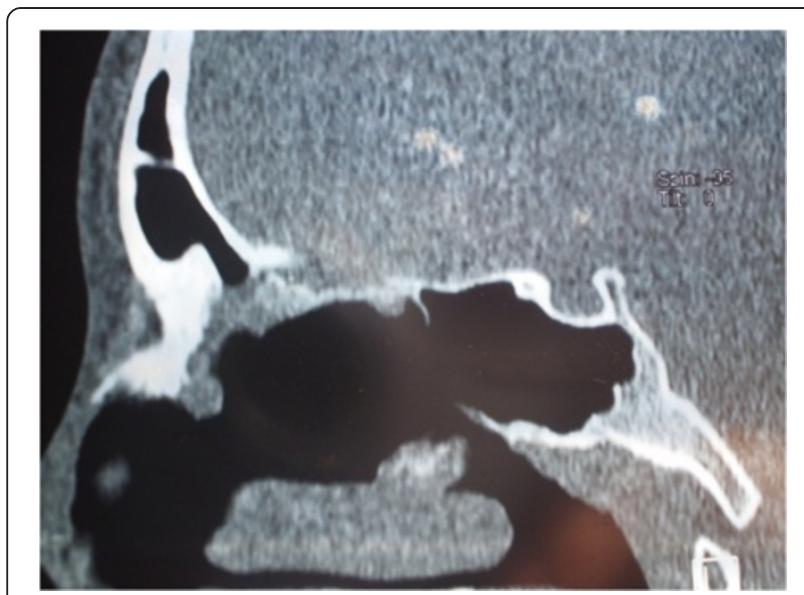

Figure 6 Sagittal multislice computed tomography one year postoperatively.

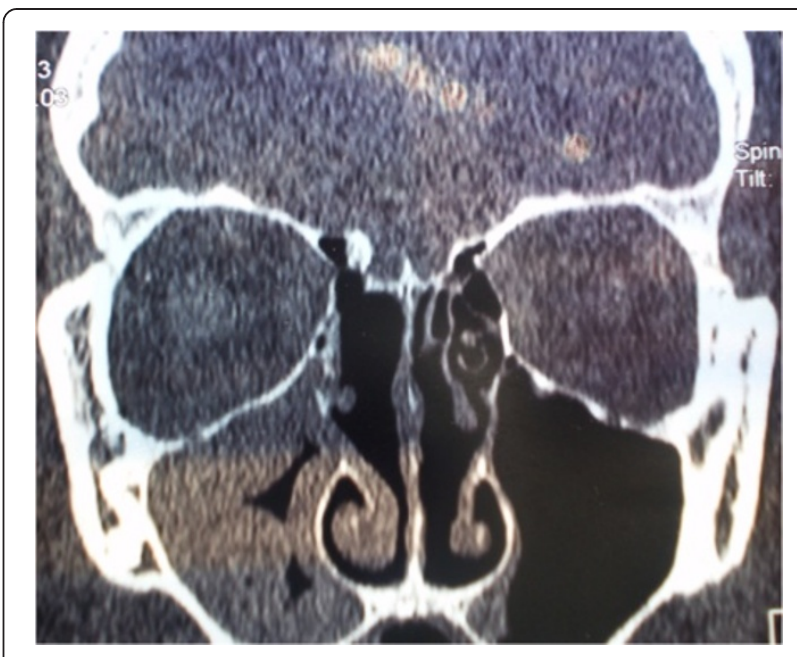

Figure 7 Coronal multislice computed tomography one year postoperatively.

Osteomas are often asymptomatic and are frequently an incidental finding. They are round, oval, white, well circumscribed and attached to the underlying bone by a broad base, or occasionally by a small stalk. On bisection, they are dense or sclerotic, with narrow (compact type) or prominent (spongiotic) intertrabecular spaces. Recurrences are very rare, even in incompletely excised lesions. Malignant transformation has not been reported.

Osteoid osteoma is 1 to $2 \mathrm{~cm}$ in diameter, and morphologically similar lesions larger than $2 \mathrm{~cm}$ are classified as osteoblastomas [1,5]. It accounts for approximately 12 percent of benign bone tumors and, similar to osteoblastoma, it predominantly affects children and young adults, particularly female. Clinically, osteoid osteoma most commonly occurs in the long bones (for example, femur, tibia). The lesions cause night pain that is relieved with nonsteroidal anti-inflammatory drugs (NSAIDs). On

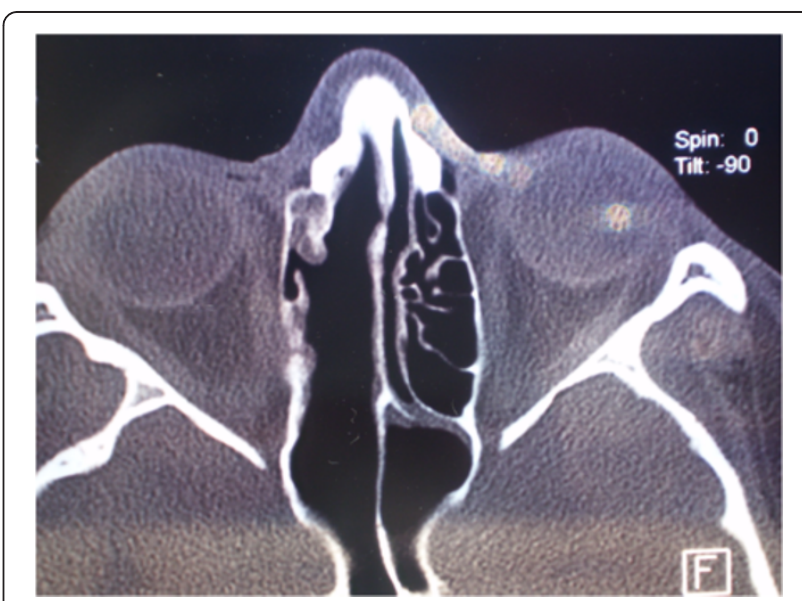

Figure 8 Axial multislice computed tomography one year postoperatively. 
radiography, osteoid osteomas exhibit a central lucency (the nidus) with patchy mineralization located centrally. Osteoid osteoma may be managed nonsurgically with NSAIDs.

Osteosarcoma is the most common primary malignant tumor of bone. In the craniofacial region, osteosarcoma mostly affects jaw bones, with approximately 6 percent of all [15]. The majority of patients are older than 30 years of age. On radiography, osteosarcoma shows a poorly defined destructive lesion that can be sclerotic, lytic or mixed.

Osteoblastoma occurs predominantly in young adults. It develops most frequently in the posterior element of the vertebrae and in long bone metaphyses. Patients present with a painful mass and craniofacial tumors may produce headache, tooth impaction and epistaxis. The pain does not get worse at night and is less likely to be relieved with NSAIDs. Most osteoblastomas measure between 2 and $5 \mathrm{~cm}$ and are solid, dark red, due to the rich vascularity, tan-white and gritty. Some tumors have more poorly defined margins. On radiography, osteoblastomas arise in the medullary cavity or on the surface of the bone. The intralesional mineralization is very variable and may be minimal or extensive, but is greatest centrally. The intertrabecular space is filled with richly vascular loose connective tissue. The treatment of osteoblastoma is principally surgical excision. En bloc resection is usually curative, however, curettage results in a local recurrence rate of approximately 20 percent. Malignant transformation of osteoblastoma to osteosarcoma is exceptionally rare ( $<1$ percent).

Reliable preoperative diagnosis is of utmost importance, which is rather difficult in bone tumors because cytologic biopsy is impossible due to the hard tumor structure. Biopsy can be done in osteoblastoma, however, hemorrhage may occur because of rich tumor vascularization. It is crucial to differentiate osteoid osteoma from osteoblastoma because the former can be managed by medicamentous therapy (NSAIDs), whereas surgical treatment is the only therapeutic option for osteoblastoma.

\section{Conclusions}

To the best of our knowledge, this is the first case of middle turbinate osteoblastoma with intracranial spread. Surgical treatment is the only therapeutic option for osteoblastoma.

\section{Consent}

Written informed consent was obtained from the patient's parents for publication of this case report and any accompanying images. A copy of the written consent is available for review by the Editor-in-Chief of this journal.
Competing interests

The authors declare that they have no competing interests.

\section{Authors' contributions}

DC was the surgeon, participated in the sequence alignment and drafted the manuscript. ZC participated in the sequence alignment. BL participated in the design of the study and performed the statistical analysis. MK conceived of the study, and participated in its design and coordination and helped to draft the manuscript. All authors read and approved the final manuscript.

\section{Author details}

${ }^{1}$ Department of Othorinolaryngology, University Hospital Split, Spinčićeva 1, 21000 Split, Croatia. ${ }^{2}$ Department of Pediatrics, University Hospital Split, Spinčićeva 1, 21000 Split, Croatia.

Received: 20 November 2013 Accepted: 26 February 2014 Published: 23 May 2014

\section{References}

1. Atesok Kl, Alman BA, Schemitsch EH, Peyser A, Mankin H: Osteoid osteoma and osteoblastoma. J Am Acad Orthop Surg 2011, 19:678-689.

2. Nielsen GP, Rosenberg AW: Update on bone forming tumors of the head and neck. Head Neck Pathol 2007, 1:87-93.

3. Lichtenstein L: Benign osteoblastoma. Cancer 1956, 9:1044.

4. Jaffe HL: Benign osteoblastoma. Bull Hosp J Orthop Inst 1956, 17:141-151.

5. Janin Y, Epstein JA, Carras R, Khan A: Osteoid osteomas and osteoblastoma of the spine. Neurosurgery 1981, 8:31-38.

6. Myles ST, MacRae ME: Benign osteoblastoma of the spine in childhood. J Neurosurg 1988, 68:884-888.

7. Arantes M, Resende M, Honavar M, Pires MM, Pereira J, Vaz AR: Benign osteoblastoma of the sphenoid bone. Skull Base 2009, 19:437-441.

8. Yong GL, Chang WC: Benign osteoblastoma located in the parietal bone. J Korean Neurosurg Soc 2010, 48:170-172.

9. Young E, Dabrowski M, Brelsford K: Osteoblastoma of the nasal septum. J Laryngol Otol 2011, 125:1062-1066.

10. Jeong YJ, Sohn MH, Lim ST, Kim DW, Jeong HJ, Jang KY, Yim CY: Osteoblastoma in the nasal cavity: F-18 FDG PET/CT and Tc-99 m MDP 3-phase bone scan findings with pathologic correlation. Clin Nucl Med 2011, 36:214-217.

11. Ducastelle T, Dehesdin D, Hemet J, Andrieu-Guitrancourt J: Benign subperiostealosteoblastoma of the nasal cavity, histological and ultrastructural study of a case. Ann Pathol 1985, 5:131-136.

12. Chang $Y K$, Chen PR, Su B, Lee CL: Osteoblastoma of the inferior turbinate. Otolaryngol Head Neck Surg 2011, 145:517-518.

13. Avadhanam PK, Vuyyur S, Panigrahi MK: A rare occurrence of osteoblastoma in a child. J Pediatr Neurosci 2010, 5:153-156.

14. Daneshi A, Jalessi M, Behzadi AH: Middle turbinate osteoma. Clin Exp Otorhinolaryngol 2010, 3:226-228.

15. Klein MJ, Siegal GP: Osteosarcoma: anatomic and histologic variants. Am J Clin Pathol 2006, 125:555-581.

doi:10.1186/1752-1947-8-161

Cite this article as: Cikojević et al:: Aggressive middle turbinate osteoblastoma with intracranial extension: a case report. Journal of Medical Case Reports 2014 8:161.

\section{Submit your next manuscript to BioMed Central and take full advantage of:}

- Convenient online submission

- Thorough peer review

- No space constraints or color figure charges

- Immediate publication on acceptance

- Inclusion in PubMed, CAS, Scopus and Google Scholar

- Research which is freely available for redistribution 